\title{
Prevalence and Associated Factors of Low Back Pain Among Hairdressers in Female Beauty Salons of Mekelle City, Tigray, Ethiopia; Cross-Sectional Study.
}

Gebrerufael Solomon Tsegay ( $\sim$ rafa.sol04@gmail.com )

Mekelle University College of Health Sciences https://orcid.org/0000-0003-2120-8233

Berihu Fisseha Gebremeskel

Mekelle University College of Health Sciences

\section{Selam Desalegn Gezahegn}

Mekelle University College of Health Sciences

Desalegn Massa Teklemichael

Mekelle University College of Health Sciences

\section{Research article}

Keywords: Low back pain, Hairdresser, Musculoskeletal disorder.

Posted Date: September 18th, 2019

DOI: https://doi.org/10.21203/rs.2.14568/v1

License: @ (i) This work is licensed under a Creative Commons Attribution 4.0 International License. Read Full License 


\section{Abstract}

Abstract

Background: Low back pain is one of the most prevalent musculoskeletal conditions and the most common cause of disability. Hairdressers are one of the high-risk professionals for work-related musculoskeletal disorders like low back pain. However, studies on the prevalence and associated factors of low back pain among hairdressers are scarce. The objective of the current study is to assess the prevalence and associated factors of low back pain among hairdressers in female beauty salons of the Mekelle City, Tigray, Ethiopia.

Method: An institutional-based cross-sectional study was employed from January 05 up to February 28,2018 . The sample $(n=344)$ hairdressers were selected randomly from all-female beauty salons of Mekelle city. A structured questionnaire adapted from a standardized Nordic questionnaire and other similar studies was used. Binary logistic regression analysis was performed to identify factors associated with low back pain. The Adjusted Odds Ratio (AOR) with a 95\% Confidence Interval (Cl) was estimated to show the strength of association. A p-value of < 0.05 was used to declare statistical significance.

Result: A total of 314 hairdressers participated, with a $91.3 \%$ response rate. The study found that the self-reported 12 months prevalence of low back pain was (47.5\%) with 95\% Cl (41.8- 53.1). Awkward way working posture [AOR: $2.6,95 \% \mathrm{Cl}(1.41-4.62)$ ], working greater than 4 days in a week [AOR: 7.98, 95\% Cl (2.54-25.09], hair washing job category [AOR: $4.35,95 \% \mathrm{Cl}(1.87-10.12)$ ], having adjustable washing basin [AOR: $0.30,95 \% \mathrm{Cl}(0.151-0.587)$ ] and job stress [AOR: $2.75,95 \% \mathrm{Cl}(1.61-4.72)]$ were factors that shows a statically significant association with low back pain.

Conclusion: This study found that almost half of the hairdressers developed work-related low back pain in the last 12 months. Awkward posture, working days per week, hair washing job category, adjustable height washing basin and job stress show a significant association with low back pain. To address the problem responsible body needed to promote health and prevent low back pain among hairdressers by paying great attention to the prevalent problem and the identified risk factors.

Keywords : Low back pain, Hairdresser, Musculoskeletal disorder.

\section{Background}

Low back pain (LBP) is a common health problem, which most people experience at some point in their lifetime(1). Back pain can be categorized into specific or non-specific back pain. Non-specific back pain is diagnosed when the cause of the back pain is unknown and specific back pain refers to a specific cause for the pain, for example, an infection or a fracture(2). LBP can be acute, sub-acute or chronic, affecting all ages from children to elderly and is a very common reason for medical consultations(3).

The 2010 global burden of disease study estimated that low back pain ranked highest in terms of years lived with disability (YLDs), and sixth in terms of overall burden disability-adjusted living years (DALYs)(4). It has a numerous economic burden on individuals, families, communities, and country in general with the estimated point prevalence range from $1.0 \%$ to $58.1 \%$, and 1 -year prevalence from $0.8 \%$ to $82.5 \%$ globally(1). 
[7]Although it was largely thought of as a problem confined to western countries; LBP is also a major problem in low and middle-income countries(5). In Ethiopia, researches are available in the literature on low back pain, especially among professionals like nurses, teachers and taxi drivers with 12-month prevalence ranging (45 - $71 \%)$ (6-8). LBP may be associated with different biomechanical factors (heavy physical work, awkward static and dynamic working postures, and lifting), psychosocial factors (low level of job control, high psychological demands, and high work dissatisfaction) and individual factors (younger age, female gender, black or African American race, smoking, high BMl, and co-morbidity)(9).

Hairdressing is one of the high-risk occupations to sustain low back pain. According to a study in the USA, hairdressers were one of the top 15 high-risk occupations for back pain attributed to activities at work in females among 45 major occupations(10). In the African continent, a study from Nigeria and Egypt shows that low back pain was one of the highly prevalent work-related musculoskeletal disorders among hairdressers with annual prevalence $(76.3 \%)$ and $(12.5 \%)$ respectively $(11,12)$. In Ethiopia, one study found that the prevalence of workrelated musculoskeletal disorder was $76.6 \%$ and the low back was one of the most commonly affected body parts that account $71.5 \%$ among the hairdressers of Addis Ababa. (13)

Despite the hairdressing salon, businesses are growing in number and the professionals are prone to low back pain, epidemiological studies that assess the magnitude of LBP among these workers are limited and little is known about the associated factors of LBP among the hairdressers in Mekelle and other parts of Ethiopia. Implementing a rehabilitation course brought a good outcome on the musculoskeletal pain value and prevention after 1.5 years of follow-up among Finland hairdressers who had visited a physician and a physiotherapist(14). Therefore, identifying the associated factors is essential for prevention, providing rehabilitation courses and professional recommendation on the ergonomic and biomechanical posture for hairdressers. The main aim of this study is to determine the magnitude and associated factors that contribute to the development of LBP among workers engaged in hairdressing activity.

\section{Methods}

\section{Study design and setting}

An institutional-based cross-sectional study was conducted in Mekelle city, Tigray, northern Ethiopia from January 05 up to February 28, 2018. Mekelle city is located in the northern part of Ethiopia in Tigray national regional state, at a distance of $783 \mathrm{~km}$ from Addis Ababa. Its location is $13^{\circ} 32^{\prime \prime}$ North latitude and $399^{\circ} 28^{\prime}$ East longitude. Mekelle has a city administration, municipality, 7 sub-cities(15). According to the Tigray Bureau of trade, industry and urban development office 451 licensed and registered female beauty salons were found in the city.

\section{Study and source population}

The source populations of the study were all hairdressers working in all-female beauty salons of Mekelle city. All hairdressers who had one year and above work experience on the job and working in the sampled female beauty salons of Mekelle city were the study participants.

\section{Sample size and sampling technique}

The sample size for the study was determined using the formula of the single population proportion. Assuming $5 \%$ margin of error (d), 95\% confidence level (alpha, $a=0.05$, two-tailed), prevalence $71.5 \%$ (13). Finally, the sample 
size $(n=344)$ was obtained by the addition of a $10 \%$ non-response rate.

There were 451 female beauty salons registered by license registration of the Tigray Bureau of trade, industry and urban development office. The registration list contains the name and address of the beauty salons. The sample, 344 beauty salons were selected using simple random sampling by a lottery method using the name of beauty salons from the list. Then the sample 344 hairdressers were collected randomly from the selected female beauty salon.

\section{Data collection and quality control}

An interviewer-administered questionnaire was used. The questionnaire was first prepared in English then translated into the local language "Tigrigna" and then back to English to ensure consistency. The data collection tool was pretested in $10 \%$ of the sampled population. Some modification on the questioners was done and the same understanding in all the data collectors was created. The questions to detect the self-reported low back pain were adapted from the standardized Nordic questionnaire (16). Questions adapted from other studies with some modification was used to assess the socio-demographic, working environment and psychosocial status of the participants. The psychosocial factors job satisfaction and job stress were measured using the 9 items of job satisfaction scale as yes (32 - 50) and no $(10-31)(17)$ and the workplace stress by 8 item scale as yes with a total score of $(16-40)$ and no ( $\leq 15)(18)$.

Eight data collectors (physiotherapists and nurses) and two supervisors (physiotherapists) were involved in this data collection. Both the data collectors and supervisors had taken two days of training before the actual data collection time about all aspects of data collection tools, questioning techniques, and ethical issues. The collected data were checked out for completeness and clarity by the principal investigator and supervisors. Data cleanup and cross-checking were done before analysis.

\section{Data analysis}

Data were entered, coded, cleaned and analyzed using the IBM Statistical Package for Social Sciences (SPSS) version 23 for windows. Mean with its standard deviation and median with its range were determined to summarize and present numeric variables. Summarized frequencies and proportions of categorical variables were presented using text and tables.

The logistic regression model was used to identify factors associated with low back pain. Independent variables with a $p$-value less than $<0.25$ in the bivariate logistic regression were fitted into the multivariate logistic regression for controlling the possible main effect of confounders and are reported using CORs. Model fitting was checked using log-likelihood, Hosmer and Lemeshow goodness of fit test. Finally, variables with $\mathrm{P}<0.05$ in the multivariate analysis were considered statically significant and presented by AOR with 95\% C. I.

\section{Operational definition}

Low back pain: A work-related low back pain which is self-reported pain, ache or discomfort for at least 2 working days during the last 12 months in the lower back. These symptoms often appear and aggravated at work that disappears during rest and after work ends (19). 


\section{Results}

Socio-demographic/Individual characteristics of hairdressers

There were 344 sampled hairdressers participated in this study giving a response rate of $314(91.3 \%)$ of the total study participants. The majority of the hairdressers $289(92 \%)$ were females with the mean age of $25.3 \pm 4.1$ years. Most of the hairdressers were single $218(69.4 \%)$ and have no child $223(71 \%)$. Regarding the educational status of the hairdressers, $183(58.3 \%)$ attended secondary school (9-12). The median monthly income for the hairdressers was 2000 Ethiopian Birr with a range of 300 to 10,000. 239 (76.1\%) of the participants were served less than 5 years with a median year for 3 years, minimum and maximum of 1 and 16 years respectively. The majority of the participants $284(79.0 \%)$ had a healthy or normal body mass index (BMI). Only $27(8.6 \%)$ of the participants have the practice of physical activity and all of them were non-smokers (Table: 1).

\section{Working environment and Ergonomic characteristics of the hairdressers}

The majority of hairdressers 280 (89.2\%) were performing their hairdressing activity in a standing position for greater than two hours per day and $219(69.7 \%)$ of the participants used awkward posture (bending or twisting uncomfortably) to perform their tasks. Out of the participants, $226(72 \%)$ worked on the same (static) position for at least 2 hours per day. The majority of the participants $282(89.8 \%)$ work for more than 4 days per week and have 1 to 5 numbers of customers per day with the median number of (5.0) customers. Hairdressers were asked about the height of the tools used in the salon, 64 (20.4\%) were using an adjustable chair and $241(76.8 \%)$ were using an adjustable washing basin. Two hundred sixty-one 261 (83.1\%) of the hairdressers pursued professional training from known local training centers, of which only 91 (29\%) of the hairdressers were attained formal training related to ergonomics (Table: 2).

\section{Psychosocial characteristics of the hairdressers}

Regarding psychosocial factors of the hairdressers, 161 (51.3\%) of the hairdressers were not satisfied with their current job, while 185 (58.9\%) of the hairdressers had job stress. About their relationship, 301 (95.9\%) of hairdressers reported that they had a good working relationship with their customers. Of the total study participants, $118(37.6 \%)$ had a boss on their work, out of these $100(84.7 \%)$ had a good working relationship with their boss (Table3).

\section{Prevalence of Low back pain among the hairdressers}

Out of 314 hairdressers, the prevalence of low back pain was 149 (47.5\%) with $95 \% \mathrm{Cl}$ (41.8- 53.1), in which participants reported they had pain or ache for at least 2 days in the lower back for the past 12 months and the pain was caused or aggravated during the working activity. The prevalence of LBP in those who used an awkward working posture was 121 (55.3\%). Similarly, $143(50.7 \%)$ of the hairdressers who were working greater than 4 days per week develop LBP. Among the hairdressers who participated in the hair washing job category, the prevalence was $136(50.9 \%)$. Among the participants who used an adjustable washing basin, only 103 (42.7\%) of them 
developed LBP. Additionally, 106 (57.3\%) of those who were stressed in their job develop LBP. Among the participants who had LBP 108 (72.5\%) and 68 (45.6\%) of them reported LBP affected their work and leisure time activities respectively. Five (3.4\%) of the participants with LBP changed their job or duties because of LBP (Table 4).

\section{Factors associated with low back pain}

After the bivariate logistic regression was done for each variable to limit the number of variables and unstable estimates in the final model, only variables with P-value less than 0.25 in the bivariate were taken in the multivariate analysis. The multivariate binary logistic regression analysis identified that; awkward posture, working day per week, hair washing job category, adjustable height washing basin, and job stress had a statistically significant association with LBP.

Hairdressers working on bending and twisting in awkward back posture were 2.6 times more likely to develop LBP than those not working on awkward back posture [AOR: 2.6, 95\% Cl (1.41-4.62)]. Participants who work more than 4 days in a week were 7.98 times more likely to develop LBP than those who work less than or equal 4 days [AOR: $7.98,95 \% \mathrm{Cl}(2.54-25.09]$. Hairdressers who work in the hair washing job category were 4.35 times more likely to develop LBP than those who were not working as washing job categories [AOR: 4.35, 95\% Cl (1.87-10.12)]. Hairdressers who used washing basin with adjustable height were $70 \%$ less likely to develop LBP compared to those who were not used [AOR: $0.30,95 \% \mathrm{Cl}(0.151-0.587)$ ]. Participants who had job stress were 2.75 times more likely to develop LBP than those who were not stressed on their job [AOR: 2.75, 95\% Cl (1.61-4.72)] (Table 4).

\section{Discussion}

The study was designed to evaluate the prevalence and associated factors of the LBP among hairdressers in Mekelle city, Tigray Ethiopia. This study found that the prevalence rate of LBP within the past 12 months was (47.5\%) which is comparable with studies done in, South Africa, Brazil, Greece and United Kingdom (39\%-53\%) (20-23). The prevalence was higher compared to the studies conducted in Ibadan Southwest Nigeria, France, and Egypt which were $(12.5 \%-31 \%)(12,24,25)$. However, it is lower relative to studies done in Taiwan, Nigeria and Addis Ababa, Ethiopia $(71.5 \%$ - 83\%) $(11,13,26)$. The difference might be due to differences in sample size, the definition of low back pain, study area, workload and the difference in assessment tools of the studies. Example, The study conducted in Egypt, that reported a low prevalence of LBP (12.5\%) was a comparative study with a small sample size among 80 hairdressers and 50 office workers(12). On the other way hairdressers in Addis Ababa, Ethiopia showed more prevalence of $\operatorname{LBP}(71.5 \%)$ than this study(13). It could be due to more sample size or as the participants were from the capital city of the country they might be open enough to report their pain. In general, the high prevalence of LBP among hairdressers might be due to the stress imposed on the lower vertebral structures by working in prolonged bending and twisting in awkward way working posture. This was supported by the study in the USA, on which hairdressers were one of the top 15 high-risk occupations for back pain among 45 major occupations(10).

In this study, the majority of the hairdressers, $72.5 \%$ and $45.6 \%$ of those with LBP reported that LBP affected their working and leisure time activities respectively. The United States Bureau of labor statistics found that $53 \%$ reported taking sick leave and $10 \%$ of them got a permanent work disability pension as a result of back pain(27). Similarly, studies conducted in Greece cosmologist, UK, and Egypt hairdressers indicate LBP affected carrying out 
normal activities and absence from work was indicated because of $\operatorname{LBP}(12,20,21)$. This may show that LBP has a negative impact on the economic, social and productivity of hairdressers.

This study found that hairdressers working on bending and twisting in awkward back posture were more likely to develop LBP. This is supported by the study conducted among Egypt and Brazil hairdressers(12, 22). Incorrect body mechanics during tasks such as bending, turning and focusing on the task places stress on the highly mobile lumbosacral part of the spine(23). Bending incorrectly places a mechanical strain on the posterior longitudinal ligament, which results in stress on the facet joints thereby resulting in $\operatorname{LBP}(23,28)$. On the contrary, awkward posture was not significantly associated with the musculoskeletal study conducted in Addis Ababa, Ethiopia(13). This might be due to the difference in hairdressing style in different settings and variation in hairdressers' awareness towards comfortable body posture when performing tasks and availability of modernized ergonomic tools.

In this study hairdressers who spent more working days in a week (more than 4 days) in hairdressing, activity was more likely to develop LBP which is consistent with two studies conducted in Nigeria(11, 25). But not among the Taiwanese hairdressers(26). The possible explanation could be as the number of working days increased, the number of customers or workload exceeds this may expose the hairdressers to the risk factors of LBP repeatedly. The study on which the majority of participants worked more days per week indicated that hours spent working per week correlated significantly $(p=0,002)$ with how participants bent during their tasks, using their backs rather than their hips and knees(29). This may result in muscle fatigue, decrease fitness and increase pain or discomfort in the musculoskeletal system.

Hairdressers who work in the hair washing job category were more likely to develop LBP in this study. It might be due to the washing job category more involves the bending and twisting movements of the spine that can lead to mechanical LBP. This is supported by the study from the USA which reported the prevalence of back pain increased as the time spent on repeated strenuous physical activities and the time spent on repeated bending, twisting, or reaching on a typical job is increased(10). On the other way, hairdressing tasks do not significantly affect discomfort in body regions of Taiwanese hairdressers(26). The difference might be the economical difference between the countries which may affect to get the latest and adjustable hairdressing tools.

This study found that hairdressers who used a washing basin with adjustable height were less likely to develop LBP or had a preventing role compared to those who were not used. Similarly, the incidence of back pain was significantly lower in those hairdressers who used ergonomically adjusted types of equipment(13, 23). An ergonomically correct washing basin is easily adjustable and maneuverable and allows for easy and regular changes in posture, thereby breaking the chain of a sustained position(23). The possible explanation maybe when the height is adjustable to the height of hairdressers the spine will be in an upright or erect position that could decrease the awkward or uncomfortable posture of the hairdressers. A study on ergonomic analysis of a hair salon revealed that fixed-height chairs and tables could put hairdressers in uncomfortable positions like twisting and bending to reach the different hairdressing materials $(28,29)$.

Hairdressers who had job stress in this study were more likely to develop LBP this is supported by the study conducted among France hairdressers and WHO report, psychosocial factors appear to play a substantial role in the frequency of low back pain $(2,24)$. Similarly, job stress was one of the psychosocial demands associated with increased risk of LBP(31). It might be those who were stressed in their job had different physical influences and workloads that may affect the occurrence of LBP. 
This research addressed one of the major occupational health problems among the neglected group of hairdressing workers. However, as it is 12-month self-reported pain or discomfort there might be recall bias, hence there might be over and underestimation of the magnitude of LBP. These could lead to a possible variation in the estimation of association among LBP and other variables. It is also a cross-sectional study design, in which the temporal occurrence of LBP outcomes cannot be proved and the study also lacks a comparison group. It is advised in future research projects to analyze in-depth by considering postural assessment and measure the ergonomic tools.

\section{Conclusion}

This study has shown that low back pain is a common work-related health problem among hairdressers. Working in awkward postures, more working days per week, hair washing job category and job stress show statistically significant association with low back pain, whereas using adjustable height washing basin has a protective effect for low back pain. Responsible bodies are recommended to give attention to promoting health and prevent low back pain among hairdressers by giving on job training related to comfortable working posture and utilization of ergonomically designed tools.

\section{Abbreviations And Acronyms}

AOR: Adjusted Odds Ratio; BMI: Body mass index; Cl: Confidence Interval; COR: Crude Odds Ratio; DALYs:

Disability-adjusted living years; LBP: Low back pain; MSD: Musculoskeletal disorder; RBTR: Repeated bending, twisting, or reaching; SPSS: Statistical Package for Social Sciences; WHO: World Health Organization; WRMSD: Work-related musculoskeletal disorder; YLDs: Years lived with disability.

\section{Declarations}

\section{Acknowledgments}

The authors would like to acknowledge the Mekelle University College of health sciences for funding the research. We also like to express special thanks to the national, regional state of Tigray Bureau of trade, industry and urban development as they provide us the necessary data about the number of salons in each sub-city. The authors would also like to acknowledge, the study participants, data collectors and supervisors of the study.

\section{Ethics approval and consent to participate}

Ethical clearance was obtained from the ethical review committee of the College of Health Sciences of Mekelle University. Written informed consent was obtained from each of the study participants after being informed in detail about the objective, purpose, benefit, risk, and the confidentiality of the information and the voluntary nature of participation. Besides, participants who had severe low back pain during the data collection time were advised and referred, for further care to the department of physiotherapy, Ayder Comprehensive Specialized Hospital.

\section{Consent for Publication}

Not applicable. 
Data will be available upon request from the corresponding author.

Competing interests

The authors declare that they have no competing interests.

Funding

This study was funded by Mekelle University. The views presented in the article are of the authors and not necessarily express the views of the funding organization. The funders were not involved in the design of the study, data collection, analysis, and interpretation.

\section{Authors' contribution}

GST* and SDGdesigned the study, developed the tool and coordinated the data collection activity. GST*, BFG, and DMT revised the proposal, carried out the statistical analysis, interpretation of the finding and writing of the manuscript. All authors read and approved the final manuscript.

\section{Authors'information}

Gebrerufael Solomon Tsegay - BSc PT, MSc PT, Lecturer of Physiotherapy, School of Medicine, College of Health Science and Ayder Comprehensive Specialized Hospital, Mekelle University, Mekelle, Ethiopia.

Berihu Fisseha Gebremeskel - BSc PT, MSc PT, Assistant professor of Physiotherapy, School of Medicine, College of Health Science and Ayder Comprehensive Specialized Hospital, Mekelle University, Mekelle, Ethiopia.

Desalegn Massa Teklemichael-MPH in Epidemiology, School of Public Health, College of Health Science, Mekelle University, Mekelle, Ethiopia.

Selam Desalegn Gezahegn - BSc PT, MPH in Reproductive Health, Ph.D. fellow, School of Medicine, College of Health Science and Ayder Comprehensive Specialized Hospital, Mekelle University, Mekelle, Ethiopia.

\section{References}

1. Hoy D, Brooks P, Blyth F, Buchbinder R. The epidemiology of low back pain. Best practice \& research Clinical Rheumatology. 2010;24(6):769-81.

2. Duthey B. Priority medicines for Europe and the world:"a public health approach to innovation". WHO Background paper. 2013;6.

3. Duthey B. Background paper 6.24 low back pain. World Health Organisation (WHO)(ed) Priority medicines for Europe and the world 'A public health approach to innovation' Geneva: WHO. 2013.

4. Hoy D, March L, Brooks P, Blyth F, Woolf A, Bain C, et al. The global burden of low back pain: estimates from the Global Burden of Disease 2010 study. Annals of the rheumatic diseases. 2014: annrheumdis-2013204428.

5. Jackson T, Thomas S, Stabile V, Han X, Shotwell M, McQueen K. Prevalence of chronic pain in low-income and middle-income countries: a systematic review and meta-analysis. The Lancet. 2015;385: S10. 
6. Sikiru L, Shmaila H. Prevalence and risk factors of low back pain among nurses in Africa: Nigerian and Ethiopian specialized hospitals survey study. East African journal of public health. 2009;6(1).

7. Beyen T, Mengestu M, Zele Y. Low back pain and associated factors among teachers in Gondar Town, North Gondar, Amhara Region, Ethiopia. Occup Med Health Aff. 2013;1(5).

8. Yitayeh A, Mekonnen S, Fasika S, Gizachew M. Annual Prevalence of Self-Reported Work Related Musculoskeletal Disorders and Associated Factors among Nurses Working at Gondar Town Governmental Health Institutions, Northwest Ethiopia. Emerg Med (Los Angel). 2015;5(227):2.

9. Da Costa BR, Vieira ER. Risk factors for work-related musculoskeletal disorders: a systematic review of recent longitudinal studies. American journal of industrial medicine. 2010;53(3):285-323.

10. Guo H-R. Working hours spent on repeated activities and the prevalence of back pain. Occupational and environmental medicine. 2002;59(10):680-8.

11. Aweto HA, Tella BA, Johnson OY. Prevalence of work-related musculoskeletal disorders among hairdressers. International journal of occupational medicine and environmental health. 2015;28(3):545-55.

12. Hassan O, Bayomy H. Occupational respiratory and musculoskeletal symptoms among Egyptian female hairdressers. Journal of community health. 2015;40(4):670-9.

13. Bedru W, Tefera Y, Wakuma S. Self-Reported Work-Related Musculoskeletal Disorders and Determinant Factors Of Female Beauty Salon Hair Dressers, 2016.

14. Nevala-Puranen N, Halonen M, Tikkanen R, Arokoski J. Changes in hairdressers' work techniques and physical capacity during rehabilitation. Occupational ergonomics. 1998;1(4):259-68.

15. Administration Mc. [Cited 2017 November 23]; Available from http://www.mwud.gov.et/web/mekele/home

16. Kuorinka I, Jonsson B, Kilbom A, Vinterberg H, Biering-Sørensen F, Andersson G, et al. Standardised Nordic questionnaires for the analysis of musculoskeletal symptoms. Applied ergonomics. 1987;18(3):233-7.

17. Macdonald S, Maclntyre P. The generic job satisfaction scale: Scale development and its correlates. Employee Assistance Quarterly. 1997;13(2):1-16.

18. Harris-Roberts J. Available from https://www.stress.org/wp-content/uploads/2011/08/2001Attitude-in-theWorkplace-Harris.pdf.

19. Statistics. BoL. Injuries, Illnesses, and fatalities. Occupational Safety and Health Definition. 2007.

20. Tsigonia A, Tanagra D, Linos A, Merekoulias G, Alexopoulos EC. Musculoskeletal disorders among cosmetologists. International journal of environmental research and public health. 2009;6(12):2967-79.

21. Bradshaw L, Harris-Roberts J, Bowen J, Rahman S, Fishwick D. Self-reported work-related symptoms in hairdressers. Occupational medicine. 2011;61(5):328-34.

22. Mussi G, Gouveia N. Prevalence of work-related musculoskeletal disorders in Brazilian hairdressers. Occupational medicine. 2008;58(5):367-9.

23. Puckree T. Musculoskeletal pain in the hairdressers-a study in Durban. Journal of Community and Health Sciences. 2009;4(2).

24. Deschamps F, Langrand J, Lesage F-X. Health assessment of self-employed hairdressers in France. Journal of occupational health. 2014;56(2):157-63.

25. Omokhodion F, Balogun M, Ola-Olorun F. Reported occupational hazards and illnesses among hairdressers in Ibadan, Southwest Nigeria. West African journal of medicine. 2009;28(1). 
26. Fang H-L, Chen RC, Fang H-P, Xu Q. An ergonomic approach to an investigation into the risk factors leading to work-related musculoskeletal disorders for Taiwanese hairdressers. Proceedings of International Association of Societies of Design Research IASDR. 2007.

27. Summers K, Jinnett K, Bevan S. Musculoskeletal disorders, workforce health and productivity in the United States. The center for workforce health and performance, Lancaster University. 2015.

28. Mahdavi S. Evaluation of the risk of musculoskeletal disorders using Rapid Entire Body Assessment among hairdressers in Khorramabad, Iran, in 2014. situations. 2013;14:15.

29. Keebler J, Schuster D, Ososky S. Ergonomic Analysis of a Hair Salon. Journal of Management and Engineering Integration. 2008;1(1).

\section{Tables}

\section{Table 1: Socio-demographic /individual characteristics of hairdressers in Mekelle city, February $2018(\mathrm{n}=314)$}




\begin{tabular}{|c|c|c|c|}
\hline \multirow[b]{2}{*}{ Variables } & \multicolumn{2}{|c|}{ Low back pain } & \multirow[b]{2}{*}{ Total N (\%) } \\
\hline & Yes N (\%) & No N (\%) & \\
\hline \multicolumn{4}{|l|}{ Gender } \\
\hline Female & $140(48.4)$ & $149(51.6)$ & $289(92.0)$ \\
\hline Male & $9(36.0)$ & $16(64)$ & $25(8.0)$ \\
\hline \multicolumn{4}{|l|}{ Age group } \\
\hline$<20$ & $11(52.4)$ & $10(47.6)$ & $21(6.7)$ \\
\hline $20-24$ & $52(39.7)$ & $79(60.3)$ & $131(41.7)$ \\
\hline $25-29$ & $58(51.8)$ & $54(48.2)$ & $112(35.7)$ \\
\hline $30-34$ & $28(56)$ & $22(44)$ & $50(15.9)$ \\
\hline \multicolumn{4}{|l|}{ Marital status } \\
\hline Married & $57(59.4)$ & $39(40.6)$ & $96(30.6)$ \\
\hline Single & $92(42.3)$ & $126(57.7)$ & $218(69.4)$ \\
\hline \multicolumn{4}{|l|}{ Number of children } \\
\hline$\leq 2$ child & $46(56.1)$ & $36(43.9)$ & $82(26.1)$ \\
\hline$>2$ child & $5(55.6)$ & $4(44.4)$ & $9(2.9)$ \\
\hline No child & $98(43.9)$ & $125(56.1)$ & $223(71.0)$ \\
\hline \multicolumn{4}{|l|}{ Educational status } \\
\hline Primary school(1-8) & $48(53.9)$ & $41(46.1)$ & $89(28.3)$ \\
\hline Secondary school(9-12) & $78(42.6)$ & $105(57.4)$ & $183(58.3)$ \\
\hline Higher education & $23(54.8)$ & $19(45.2)$ & $42(13.4)$ \\
\hline \multicolumn{4}{|l|}{ Work experience(years) } \\
\hline$\leq 2$ years & $46(39.3)$ & $71(60.7)$ & $117(37.3)$ \\
\hline 3-5 years & $65(53.3)$ & $57(46.7)$ & $122(38.9)$ \\
\hline$>5$ years & $38(50.7)$ & $37(49.3)$ & $75(23.8)$ \\
\hline \multicolumn{4}{|l|}{ Monthly income (Birr) } \\
\hline$\leq 1500$ & $52(39.1)$ & $81(60.9)$ & $133(42.4)$ \\
\hline $1501-3000$ & $62(58.5)$ & $44(41.5)$ & $106(33.8)$ \\
\hline$>3000$ & $23(47.9)$ & $25(52.1)$ & $48(15.2)$ \\
\hline \multicolumn{4}{|l|}{ Body mass index(BMI) } \\
\hline Underweight & $11(28.2)$ & $28(71.8)$ & $39(12.4)$ \\
\hline Healthy & $99(39.9)$ & $149(60.1)$ & $248(79.0)$ \\
\hline Overweight & $17(63)$ & $10(37)$ & $27(8.6)$ \\
\hline \multicolumn{4}{|l|}{ Household activity } \\
\hline Yes & $57(62)$ & $35(38)$ & $92(29.3)$ \\
\hline No & $92(41.4)$ & $130(58.6)$ & $222(70.7)$ \\
\hline \multicolumn{4}{|l|}{ Physical activity } \\
\hline Yes & $7(25.9)$ & $20(74.1)$ & $27(8.6)$ \\
\hline No & $142(49.5)$ & $145(50.5)$ & $287(91.4)$ \\
\hline
\end{tabular}

Table 2: Working environment and Ergonomic characteristics and prevalence of LBP of the female 
beauty salon hairdressers of Mekelle city, February $2018(n=314)$

\begin{tabular}{|c|c|c|c|}
\hline \multirow[b]{2}{*}{ Variables } & \multicolumn{2}{|c|}{ Low back pain } & \multirow[b]{2}{*}{ Total N (\%) } \\
\hline & Yes N (\%) & No $\mathbf{N}(\%)$ & \\
\hline \multicolumn{4}{|l|}{ Prolonged standing } \\
\hline Yes & $140(50)$ & $140(50)$ & $280(89.2)$ \\
\hline No & $9(26.5)$ & $25(73.5)$ & $34(10.8)$ \\
\hline \multicolumn{4}{|l|}{ Static posture } \\
\hline Yes & $107(47.3)$ & $119(52.7)$ & $226(72.0)$ \\
\hline No & $42(47.7)$ & $46(52.3)$ & $88(28.0)$ \\
\hline \multicolumn{4}{|l|}{ Awkward posture } \\
\hline Yes & $121(55.3)$ & $98(44.7)$ & $219(69.7)$ \\
\hline No & $28(29.5)$ & $67(70.5)$ & $95(30.3)$ \\
\hline \multicolumn{4}{|l|}{ Repeating activity } \\
\hline Yes & $51(53.7)$ & $44(46.3)$ & $95(30.3)$ \\
\hline No & $98(44.7)$ & $121(55.3)$ & $219(69.7)$ \\
\hline \multicolumn{4}{|c|}{ Working hours per day } \\
\hline $2-5$ hours & $13(28.3)$ & $33(71.7)$ & $46(14.6)$ \\
\hline 6-10 hours & $62(48.4)$ & $66(51.6)$ & $128(40.8)$ \\
\hline$>10$ hours & 74(52.9) & $66(47.1)$ & $140(44.6)$ \\
\hline \multicolumn{4}{|c|}{ Working days per week } \\
\hline$\leq 4$ days & $6(18.7)$ & $26(81.3)$ & $32(10.2)$ \\
\hline$>4$ days & $143(50.7)$ & $139(49.3)$ & $282(89.8)$ \\
\hline \multicolumn{4}{|c|}{ Number of customers per day } \\
\hline 1-5 customers & $90(45.5)$ & 108(54.5) & 198(63.1) \\
\hline 6-10 customers & $59(50.9)$ & $57(49.1)$ & 116(36.9) \\
\hline \multicolumn{4}{|l|}{ Break time in a day } \\
\hline Yes & $23(46)$ & $27(54)$ & $40(15.9)$ \\
\hline No & $126(47.7)$ & $138(52.3)$ & $264(84.1)$ \\
\hline \multicolumn{4}{|l|}{ Adjustable chair } \\
\hline Yes & $32(50)$ & $32(50)$ & $64(20.4)$ \\
\hline No & $117(46.8)$ & $133(53.2)$ & $250(79.6)$ \\
\hline \multicolumn{4}{|l|}{ Adjustable washbasin } \\
\hline Yes & $103(42.7)$ & 138(57.3) & $241(76.8)$ \\
\hline No & $46(63)$ & $27(37)$ & $73(23.2)$ \\
\hline \multicolumn{4}{|c|}{ Professional and ergonomics training } \\
\hline Yes & $34(37.4)$ & $57(62.6)$ & $91(29.0)$ \\
\hline No & $92(54.1)$ & $78(45.9)$ & $170(54.1)$ \\
\hline No training & $23(43.4)$ & $30(56.6)$ & $53(16.9)$ \\
\hline
\end{tabular}

Table 3: Psychosocial characteristics and prevalence of LBP of the female beauty salon hairdressers of Mekelle city, February $2018(\mathrm{n}=314)$ 


\begin{tabular}{|c|c|c|c|}
\hline \multirow[t]{2}{*}{ Variables } & \multicolumn{2}{|c|}{ Low back pain } & \multirow[b]{2}{*}{ Total N (\%) } \\
\hline & Yes N (\%) & No N (\%) & \\
\hline \multicolumn{4}{|l|}{ Job stress } \\
\hline Yes & 106(57.3) & $79(42.7)$ & $185(58.9)$ \\
\hline No & $43(33.3)$ & $86(66.7)$ & $129(41.1)$ \\
\hline \multicolumn{4}{|l|}{ Job satisfaction } \\
\hline Yes & $54(35.3)$ & $99(64.7)$ & 153(48.7) \\
\hline No & $95(59)$ & $66(41)$ & $161(51.3)$ \\
\hline \multicolumn{4}{|c|}{ Relationship with boss } \\
\hline Good & $37(37)$ & $63(63)$ & $100(31.8)$ \\
\hline Fair & $12(66.7)$ & $6(33.3)$ & $18(5.8)$ \\
\hline Have no boss & $100(51)$ & $96(49)$ & $196(62.4)$ \\
\hline \multicolumn{4}{|c|}{ Relationship with customers } \\
\hline Good & $140(46.5)$ & $161(53.5)$ & $301(95.9)$ \\
\hline Fair & $7(53.85)$ & $6(46.15)$ & $13(4.1)$ \\
\hline
\end{tabular}


Table 4: The adjusted effect of factors on LBP among hairdressers of Mekelle city, February 2018 (n=314) 
Variables

Low back pain
Work experience

$\leq 2$ years

3-5 years

$>5$ years

Physical activity

Yes

No

Prolonged standing

Yes

No

Awkward posture

Yes

No

Working hours per day

2-5 hours

6-10 hours

$>10$ hours

Working days per week

$\leq 4$ days

$>4$ days

Hair washing

Yes

No

Adjustable washing basin

Yes

No

Training of ergonomics

No

Yes

Not professional

Job stress

Yes

No

Job satisfaction

Yes

$\begin{array}{lllll}46(39.3) & 71(60.7) & 1.00 & & \\ 65(53.3) & 57(46.7) & 1.76(1.053- & 0.735(0.318- & 0.471 \\ & & 2.943)^{*} & 1.698) & \\ 38(50.7) & 37(49.3) & 1.585(0.883- & 1.487(0.735- & 0.270 \\ & & 2.846) & 3.005) & \end{array}$

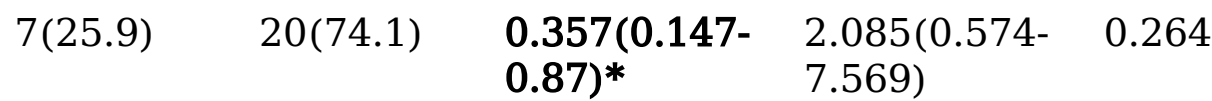

142(49.5) $145(50.5) \quad 1.00$

$\begin{array}{lllll}\text { 140(50) } & 140(50) & \mathbf{2 . 7 7 8 ( 1 . 2 5 -} & 0.976(0.343- & 0.963 \\ & & \mathbf{6 . 1 6 4})^{*} & 2.774) & \\ 9(26.5) & 25(73.5) & 1.00 & 1.00 & \end{array}$

$\begin{array}{lllll}121(55.3) & 98(44.7) & 2.95(1.765- & 2.555(1.41- & 0.002\end{array}$ 4.946)* $\quad 4.62)^{* *}$

$28(29.5) \quad 67(70.5) \quad 1.00 \quad 1.00$

\begin{tabular}{|c|c|c|c|c|}
\hline $13(28.3)$ & 33(71.7) & 1.00 & & \\
\hline $62(48.4)$ & $66(51.6)$ & $\begin{array}{l}2.385(1.15 \\
-4.945)^{*}\end{array}$ & $\begin{array}{l}0.630(0.249- \\
1.594)\end{array}$ & 0.329 \\
\hline $74(52.9)$ & $66(47.1)$ & $\begin{array}{l}2.846(1.38 \\
-5.86)^{*}\end{array}$ & $\begin{array}{l}1.111(0.610- \\
2.022)\end{array}$ & 0.73 \\
\hline
\end{tabular}

$\begin{array}{llll}6(18.7) & 26(81.3) & 1.00 & 1.00\end{array}$

$\begin{array}{llllll}143(50.7) & 139(49.3) & \mathbf{4 . 4 5 8}(1.78- & 7.97 & (2.53- & <0.001\end{array}$ 11.16)* 25.09)**

$\begin{array}{lllll}\text { 136(50.9) } & 131(49.1) & \mathbf{2 . 7 1 5 ( 1 . 3 7 -} & \mathbf{4 . 3 4 9}(\mathbf{1 . 8 7 -} & 0.001 \\ & & \mathbf{5 . 3 7 4})^{*} & \mathbf{1 0 . 1})^{* *} & \\ 13(27.7) & 34(72.3) & 1.00 & 1.00 & \end{array}$

$103(42.7) \quad 138(57.3) \quad \mathbf{0 . 4 3 8}(\mathbf{0 . 2 5 5 -} \quad \mathbf{0 . 2 9 7} \quad(\mathbf{0 . 1 5}-\quad<0.001$ 0.75)* $\quad 0.587)^{* *}$

$\begin{array}{llll}46(63) & 27(37) & 1.00 & 1.00\end{array}$

$\begin{array}{lllll}92(54.1) & 78(45.9) & 0.65(0.349- & 1.709(0.765- & 0.191\end{array}$

1.21) 3.819)

$\begin{array}{lllll}34(37.4) & 57(62.6) & \mathbf{0 . 5 0 6}(0.300- & 1.116(0.466- & 0.805\end{array}$

$\left.\mathbf{0 . 8 5 2}^{*} \quad 2.67\right)$

$\begin{array}{llll}23(43.4) & 30(56.6) & 1.00 & 1.00\end{array}$

$106(57.3) \quad 79(42.7) \quad 2.684(1.68 \quad 2.753(1.61-<0.001$

$-4.284) *$

$\begin{array}{llll}43(33.3) & 86(66.7) & 1.00 & 1.00\end{array}$

$\begin{array}{lllll}54(35.3) & 99(64.7) & \mathbf{0 . 3 7 9}(0.24 & 1.855(1.042- & 0.36\end{array}$ 


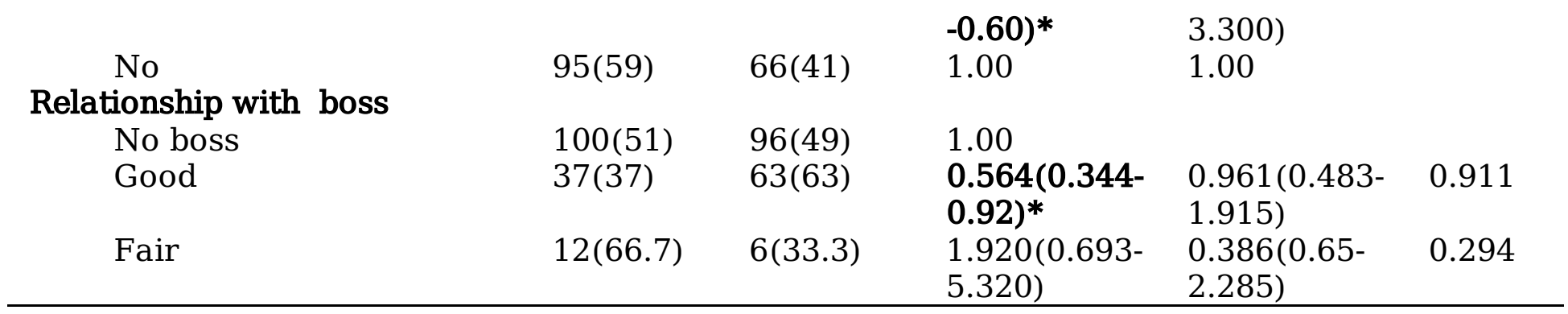

*= significant association (bivariate), **=significant association (multivariate), COR=crude odds ratio, $\mathrm{AOR}=$ adjusted odds ratio, $1.00=$ references. 